\title{
Beneficial effects of soaking and germination on nutritional quality and bioactive compounds of biofortified wheat derivatives
}

\author{
Meena Verma ${ }^{1}$, Vinod Kumar ${ }^{2}$, Imran Sheikh ${ }^{1}$, Punesh Sangwan ${ }^{3}$, Roop Singh Bora ${ }^{1 *}$, Ajar Nath Yadav ${ }^{1}$, \\ Harcharan Singh Dhaliwal ${ }^{1}$ \\ ${ }^{1}$ Department of Genetics, Plant Breeding and Biotechnology, Khem Singh Gill Akal College of Agriculture, Eternal University, Baru Sahib, India. \\ ${ }^{2}$ Department of Biochemistry, CCS Haryana Agricultural University, Hisar, India. \\ ${ }^{3}$ Akal College of Basic Sciences, Eternal University, Baru Sahib, India.
}

\begin{tabular}{l}
\hline ARTICLE INFO \\
\hline Article history: \\
Received on: February 01, 2021 \\
Accepted on: April 08, 2021 \\
Available online: September 01, 2021 \\
\hline
\end{tabular}

\section{Key words:}

Biofortified wheat derivatives, soaking, germination, wheat quality, phenolic content, anthocyanin content

\begin{abstract}
The biotechnological advances and various crop improvement strategies have contributed to a great extent in nutritional improvement of important food crops, as an intervention toward alleviating the hidden hunger for the developing countries. The development, evaluation, and utilization of biofortified wheat are of great significance to achieve the above goal. In this study, biofortified wheat lines were subjected to soaking (12 hours) and germination (upto 96 hours) at room temperature. The soluble protein and starch contents were evaluated after 12 hours of soaking. Soluble protein, starch, total phenolics, and anthocyanin contents were determined in germinated seed samples at various time intervals (i.e., 12, 24, 48, 72, and 96 hours). In ungerminated wheat, soluble protein and starch contents were observed in the range of 6.96-8.04 mg/g and $0.110-0.147 \mathrm{mg} / \mathrm{g}$, respectively, whereas, after 12 hours of soaking it was increased up to $7.15-8.18$ and $0.119-0.150 \mathrm{mg} / \mathrm{g}$, respectively. Moreover, the soluble protein content and starch were slightly improved by $26.8 \%-48.2 \%$ and $21.5 \%-50.8 \%$ of initial value, respectively, between 72 and 96 hours post-germination. In germinated wheat, the overall total phenolic and anthocyanin contents were substantially higher than that of non-germinated wheat. These results suggested that the germination has tremendous potential to improve the bioactive components and functional property of wheat flour. The improvement of the nutritional quality will help the consumers to get benefits of germinated wheat.
\end{abstract}

\section{INTRODUCTION}

The one of most important cereal crops as energy and nutrient source for humans and animals in developing countries is wheat. As a major food source, its nutritional properties are of great importance. The biofortified wheat derivatives with improved mineral contents and quality attributes have been reported recently [1-4]. An adequate amount of protein and amino acids are needed to maintain nitrogen concentration and body function. The cereal grain's average protein content varies from $8 \%$ to $15 \%$, but is poor in some essential nutrients such as lysine, leucine, and threonine, decreasing its biological importance and nutritional value. The most widespread portion of dietary carbohydrates and

*Corresponding Author

Roop Singh Bora, Department of Genetics, Plant Breeding and Biotechnology, Khem Singh Gill Akal College of Agriculture, Eternal University, Baru Sahib, India.E-mail: roopbora@yahoo.co.in the main source of dietary energy is starch [5]. The eating quality of wheat flour-based products is also influenced by starch due to its major fraction. Starch properties are influenced by plant tissue physiological environments from which starch is isolated [6].

The most important contributors to cereal grain antioxidant properties are phenolic compounds [7]. In the pericarp, free phenolic compounds are mainly present and can be isolated with organic solvents [8]. These metabolites also contribute to the antioxidant activity of crops [9]. In the Mediterranean diets, these compounds constitute $30 \%$ of the total phenol [10]. In the plant kingdom, anthocyanins are water-soluble pigments which belongs to a class of compounds identified as flavonoids [11]. The anti-cancerous, anti-inflammatory, and free radical scavenging activity have been reported in Anthocyanins [12-15]. It is, therefore, important to examine the biochemical quality of wheat derivatives for food and nutritional purposes, and for greater nutritional consistency. The development of biofortified wheat derivatives have provided a 
boost to eradicate the problem of "Hidden hunger" caused by poor micronutrient availability in the developing countries, However, the newly developed wheat derivatives are not characterized for the other quality parameters under processing conditions.

The increased metabolic activities, due to rehydration during germination is supposed to enhance the digestibility, nutritional and functional properties of grains [16,17]. Soaking is followed by sprouting or germination, at which soaked seeds are allowed to improve their nutritional benefits in a humid condition as they germinate [18]. The increased metabolites and nutritional quality of cereals have been reported during germination [19]. The present study was conducted, where different biofortified wheat genotypes were evaluated for changes in various nutritional quality parameters in response to soaking and germination as compared to untreated material.

\section{MATERIALS AND METHODS}

\subsection{Wheat Derivatives}

Seven biofortified wheat genotypes used in this study were MB-64-1-1, 48-41-23-6-4-4, 75-1-4-16-3-5, 77-46-6-8-2-1, 1-1-7-18-5-5-18, 49-1-73-8-5, and 49-1-11-9-7-1 in addition to PBW343+Lr24+GPCB1 (PBW343LrP) as parental control nonbiofortified wheat cultivar. The seed material was provided by the Department of Genetics, Plant Breeding and Biotechnology, Eternal University, Baru Sahib as an outcome of funded biofortification project.

\subsection{Sample Praparation}

Wheat seeds were sterilized at room temperature by soaking into $0.5 \%$ sodium hypochlorite at RT for 5 minutes. Thereafter, it was again soaked with $0.75 \%$ hydrogen peroxide for 5 minutes. After sterilization, the seeds were thoroughly washed and immersed in the ratio of 1:10 (w/v) distilled water) at RT for 12 hours. The soaked seed material was kept on a Petri plate under blotting paper, kept to germinate at RT up to durations of $12,24,48,72$, and 96 hours, respectively. During the germination period, the seeds were washed everyday using distilled water. At the specified intervals, the germinated seeds were collected, the roots and plumules were removed from the seed being germinated. The oven dried seeds were used for the estimation of soluble protein, starch content, total phenolics, and anthocyanin content using the standard protocols.

\subsubsection{Soluble protein content}

The amount of soluble proteins from the samples was determined by using Bradford assay [20]. $0.5 \mathrm{~g}$ of germinated and ungerminated wheat flours sample was mixed in $10 \mathrm{ml}$ of $0.1 \mathrm{M}$, sodium acetate buffer of $\mathrm{pH}$ 5. (The mixture was kept on shaker incubator for 2 hours at RT and centrifugation was carried out at 8,000 rpm for 15 minutes. The supernatant was pooled in fresh tubes as crude extract and protein estimation was carried out at $\lambda_{595} \mathrm{~nm}$ using BSA standard curve. The concentration of protein was expressed as $\mathrm{mg} / \mathrm{g}$.

\subsubsection{Starch content}

The extraction and estimation of starch content in germinated and ungerminated wheat samples was performed using protocol of Hodge and Hofreiter [21]. The absorbance was taken at $\lambda_{630}$ $\mathrm{nm}$ and a standard curve of glucose (Sigma-Aldrich) was used to determine the starch content $(\mathrm{mg} / \mathrm{g})$.

\subsubsection{Total phenolic content}

In both germinated and ungerminated samples, the extraction and estimation of total phenolic content (TPC) was performed in accordance to Chen et al. [22]. The $1 \mathrm{~g}$ sample of Wheat flour was mixed with $80 \%$ methanol $(10 \mathrm{ml})$ and kept on shaker for 2 hours at RT followed by centrifugation for 15 minutes at 3,000 $\mathrm{rpm}$ and collected the supernatant for further analysis. Gallic acid $(1 \mathrm{mg} / \mathrm{ml})$ was taken as a standard. The absorption of sample was measured at $765 \mathrm{~nm}$. The TPC (mg/g) was calculated using the formula as follows:

Total phenolic $=C^{*} V / \mathrm{m}$

where, $C=$ concentration of sample $(\mathrm{mg} / \mathrm{ml})$

$V=$ Solvent volume $(\mathrm{ml})$ used for extraction

$m=$ Sample weight $(\mathrm{g})$

\subsubsection{Total anthocyanin content (TAC)}

In germinated and ungerminated samples, the amount of total anthocyanin was determined according to Abdel-Aal and Hucl [23]. Three gram wheat sample was mixed with $24 \mathrm{ml}$ of acidified ethanol (ethanol and $\mathrm{HCl}, 85: 15, v / v$ ). The sample was mixed properly and $\mathrm{pH}$ was calibrated by using $4 \mathrm{~N} \mathrm{HCl}$ and the solution was kept on shaker at $200 \mathrm{rpm}$ for 30 minutes followed by centrifugation for 15 minutes at $4,000 \mathrm{rpm}$ and collected the aliquot to a fresh centrifuge tube with a volume made up to 50 $\mathrm{ml}$, with acidified ethanol solvent. The absorbance was measured against blank at $535 \mathrm{~nm}$ and anthocyanin concentration $(\mathrm{mg} / \mathrm{kg})$ was calculated using standard curve of cyanidin 3-glucoside $(0$ $0.02 \mathrm{mmol}$ or $0-27 \mu \mathrm{g} / 3 \mathrm{ml})$. It was calculated using following formula:

$C=(\mathrm{A} / 25,965) \times(50 / 1,000) \times 449 \times(1 / 3) \times 10^{6}$ or $C=A \times 288.21$ $\mathrm{mg} / \mathrm{kg}$

where, $C=\mathrm{TAC}(\mathrm{mg} / \mathrm{kg})$,

$A=$ absorbance

\subsubsection{Statistical analysis}

All the experiments were carried out in triplicates and the data presented are mean \pm standard deviation. The standard deviation of average was calculated by XLSTAT program (http://www. xlstat.om)

\section{RESULTS}

\subsection{Effect of Soaking and Germination on Soluble Protein Content}

In germinated and ungerminated wheat sample, the values of soluble protein content $(\mathrm{mg} / \mathrm{g})$ are shown in Figure 1. In ungerminated wheat flour, it was found to be maximum in wheat genotype 1-1$7-18-5-5-18(8.04 \mathrm{mg} / \mathrm{g})$ followed by $77-46-6-8-2-1(7.84 \mathrm{mg} / \mathrm{g})$, $75-1-4-16-3-5(7.32 \mathrm{mg} / \mathrm{g}), 49-1-11-9-7-1(7.27 \mathrm{mg} / \mathrm{g})$ and $48-41-$ 23-6-4-4 (7.12 mg/g) as compared to control PBW343LrP (7.06 


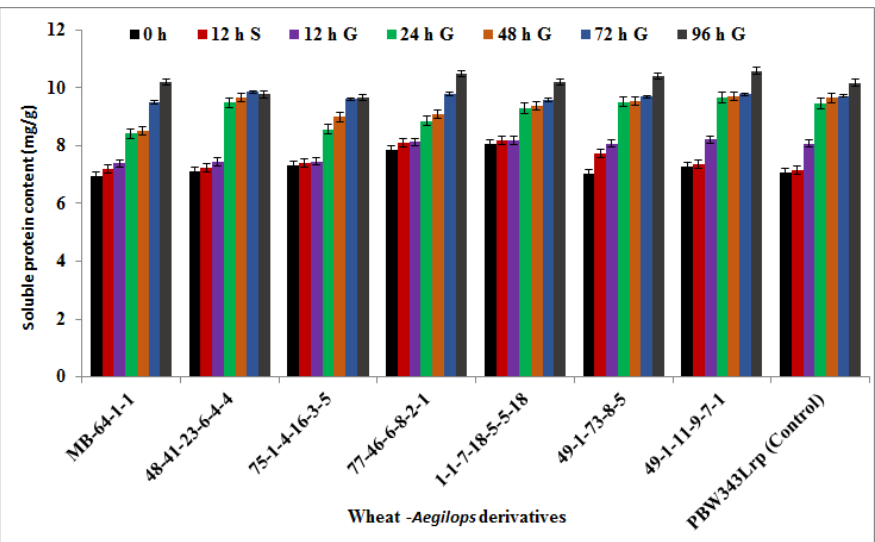

Figure 1: Effect of soaking and germination on soluble protein content of biofortified wheat-Aegilops derivatives.

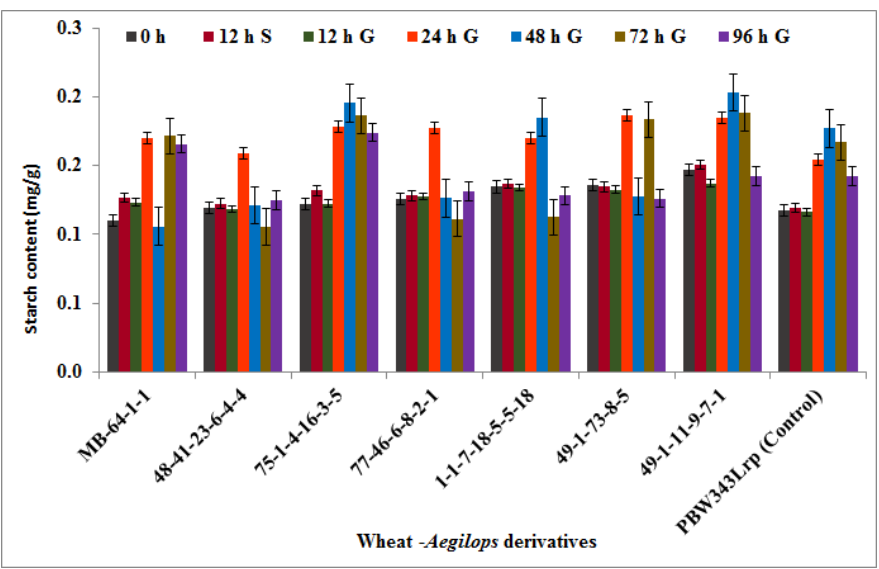

Figure 2: Effect of soaking and germination on starch content of biofortified wheat-Aegilops derivatives.

$\mathrm{mg} / \mathrm{g}$ ). At 12 hours soaking, there was an increase from $1.23 \%$ to $10.35 \%$ of the initial value and at 12 hours of germination, it was reportedly increased in the range of $1.70 \%-15.0 \%$ of initial value. During 24-48 hours of germination, it was increased in the range of $16.1 \%-36.1 \%$ of initial value. The maximum increase was reported during 72-96 hours germination, where the protein content was increased from $26.8 \%$ to $48.2 \%$ as compared to initial values in selected wheat derivatives. The soluble protein content was increased maximum in wheat derivatives 49-1-738-5 (48.2\%) followed by MB-64-1-1(46.6\%) and 49-1-11-9-7-1 $(45.6 \%)$ as compared to ungerminated samples.

\subsection{Effect of Soaking and Germination on Starch Content}

The starch content of germinated and ungerminated wheat derivatives was determined (Fig. 2). In untreated wheat flour, the starch content was found in the range of $0.110-0.147 \mathrm{mg} / \mathrm{g}$. Although the starch content was between 0.119 and $0.150 \mathrm{mg} / \mathrm{g}$, substantial variations were found in the selected samples during 12 hours of soaking. Starch content was decreased after 12 hours germination in few derivatives from approximately $-0.88 \%$ to $-2.65 \%$ of initial value, whereas it was increased slightly from the range $1.43 \%$ to $12.2 \%$ in others. At the stage of 24 hours

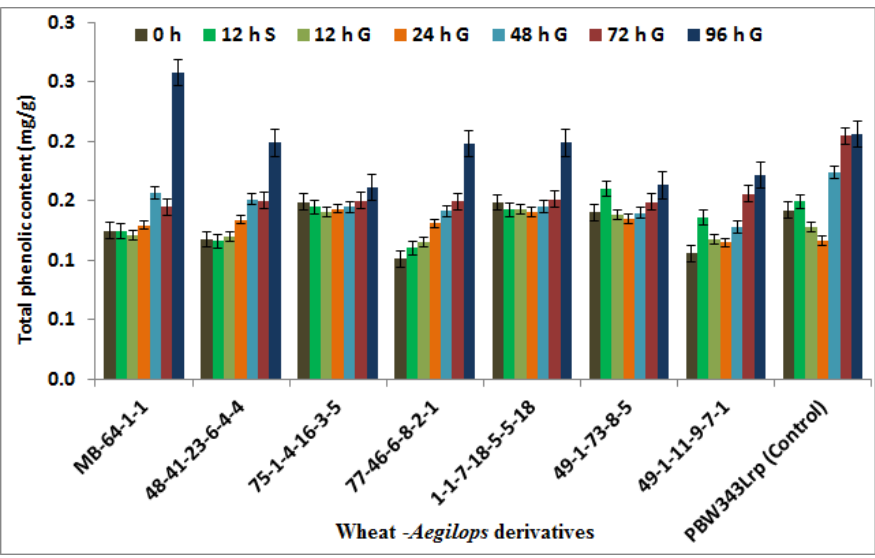

Figure 3: Effect of soaking and germination on total phenolic content of biofortified wheat-Aegilops derivatives.

germination, it was significantly increased in all derivatives from 25.3 to $54.6 \%$, while it was reduced in MB-64-1-1 (-3.75\%), 49$1-73-8-5(-6.24 \%)$ at 48 hours of germination and its content was increased in other genotypes from $1.29 \%$ to $59.7 \%$, respectively. At 72 hours germination, starch content was found to increase from $27.8 \%$ to $56.2 \%$ of initial value. A significant positive correlation was observed between 48 to 72 hours germination. Starch content was significantly increased up to $56.2 \%$, and highest increased starch content was observed during 96 hours germination in wheat derivative MB-64-1-1 (50.8\%) and 75-1-4-16-3-5 (42.2\%), respectively.

\subsection{Effect of Soaking and Germination on Total Phenolic Content}

Based on the analysis of wheat flour, the TPC was reported in the range of $0.101-0.149 \mathrm{mg} / \mathrm{g}$ in selected wheat derivatives before germination as shown in Figure 3. At the stage of 12 hours soaking, the TPC was increased in derivatives 49-1-119-7-1 (28.8\%), 49-1-73-8-5 (14\%), 77-46-6-8-2-1 (8.86\%), PBW343 $\operatorname{LrP}(5.09 \%)$, whereas, it was reduced in derivatives MB-64-1-1(-0.69 \%),48-41-23-6-4-4 (-1.31\%), 75-1-4-16-3-5 $(-2.91 \%), 1-1-7-18-5-5-18(-4.09 \%)$. After 24-, 48-, 72-, and 92hour germination, there was an increase in TPC in the range of $3.47 \%-29.4 \%, 21.1 \%-39.4 \%, 1.95 \%-47.7 \%$, and $7.96 \%-106 \%$, respectively, as compared to initial value in untreated samples. At the 96 hours of post germination stage, maximum increase in TPC was noticed in derivatives MB-64-1-1 (106\%) followed by genotypes77-46-6-8-2-1 (95.7\%) and 48-41-23-6-4-4 (69\%) as compared to ungerminated sample.

\subsection{Effect of Soaking and Germination on TAC}

The changes of the TAC $(\mathrm{mg} / \mathrm{kg})$ during germination are shown in Figure 4. In ungerminated wheat flour, TAC was noticed in the range of $31.2-78.6 \mathrm{mg} / \mathrm{kg}$, with maximum content in sample 49$1-73-8-5(78.6 \mathrm{mg} / \mathrm{kg})$ followed by $48-41-23-6-4-4(58.9 \mathrm{mg} / \mathrm{kg})$, $1-1-7-18-5-5-18$ (56.1 mg/kg), MB-64-1-1 (51.7 mg/kg), 75-1-4$16-3-5(47.7 \mathrm{mg} / \mathrm{kg})$ and least content was found in 77-46-6-8-2-1 $(29.2 \mathrm{mg} / \mathrm{kg})$ as compared to control genotype PBW343 $\operatorname{LrP}(31.2$ $\mathrm{mg} / \mathrm{kg}$ ). Analysis of 12 hours soaking samples revealed that TAC 


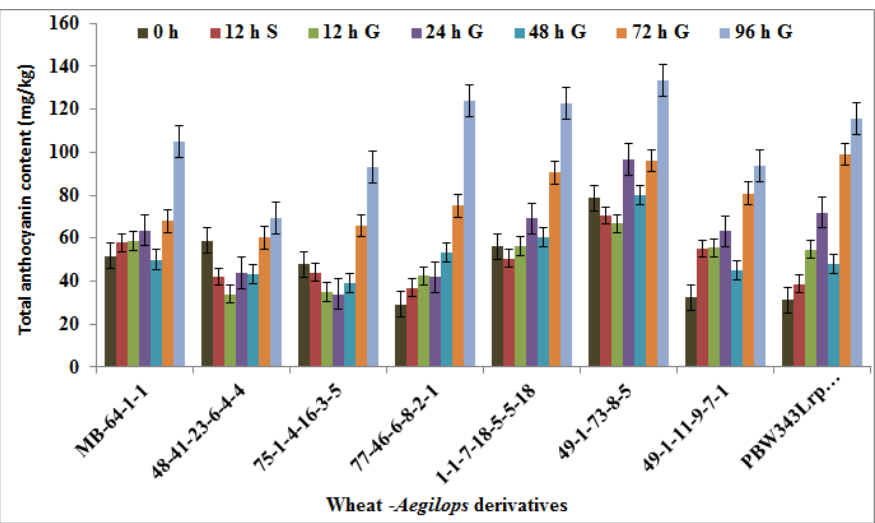

Figure 4: Effect of soaking and germination on TAC of biofortified wheatAegilops derivatives.

reported a mixed response with few samples reported increased content in the range $11.9 \%-70 \%$, whereas, there was a decrease from -7.8 to $-28.7 \%$ in some wheat derivatives. Similar trends in responses were obtained at 12-48 hours germination stages. However, at 72 hours and 96 hours germination stages, TAC was increased from $156.9 \%$ to $216.9 \%$ and $189.3 \%$ to $324.7 \%$ over ungerminated sample, respectively. The highest increase in content of total anthocyanin was observed in derivatives 77-466-8-2-1 (324.7\%) followed by PBW343 + GPC + Lr24 (271.1\%) and 49-1-11-9-7-1 (183.9\%), respectively.

\section{DISCUSSION}

The evaluation of quality attributes of cereals and other foodstuff is of great importance for its promotion and utilization. The increasing demand and trends of processed food consumption realizes the importance of better evaluation methods and multifaceted analysis. In the present study, the analysis of mineral improved wheat derivatives using sprouting and germinationbased approaches has provided an insight of associated changes under current experimental conditions. In the present investigation, soluble protein content was increased slightly during early period of germination, whereas, after 96 hours of germination, $26.8 \%$ $48.2 \%$ increase was reported. This increase might be attributed to the impact of protein hydrolysis by protease enzyme activity throughout germination of the seeds. Protein was increased in germinated flour which may be due to the synthesis of enzymes during germination, and production of certain amino acids during protein synthesis [24]. Inyang and Zakari [25] also reported that the content of protein can be increased by germination. According to Hung et al. [26], protein content of the waxy wheat sprouts did not substantially change from that of the seeds over the 48hour germination period. The protein content might also changes depending on the equilibrium of protein denaturation and protein biosynthesis during germination [27]. During germination, soluble proteins and total protein content were examined by Veluppillai et al. [28], and showed that soluble protein was increased on the 5 th day until germination of rice grains cultivated in Sri Lanka. The nutrient compositions as well as the quality of bioactive substances from cereal grains are highly affected by germination [29]. Therefore, to enhance the quality of germinated seeds, increase in germination time is necessary.
In the present study, the content of starch increased in the range of $1.72 \%-15.5 \%$ within 12 hours of soaking, however after $12-96$ hours of germination, its content was increased by $21.4 \%-50.8 \%$ in all the selected samples. In another hand, the initial value of the sample was slightly reduced in a few samples. The solubility of starches improved in wheat after 24 hours of germination relative to non-germinated wheat. Germination may have led to improved solubility by degrading starch to smaller sugars, rendering it more soluble [30]. In another side, throughout the initial stages of germination, there was a dramatic drop in starch content in barley varieties, accompanied by a slight decrease within that final stage [31]. High solubility of starch was reported in mung bean after germination for 12 hours [32]. During the germination, limited information is available on changes in the structural and physicochemical properties of starch [33]. Many other studies have proposed that germination has greatly improved the nutritional content of starch granules [6,34].

The increased TPC in this study is also in relevance to previous reports. During buckwheat germination, phenolic accumulation increased with a rise in flavonoid accumulation [35]. The overall phenol in wheat was reportedly increased by germination [8]. In sorghum, germination led to several fold increase in total phenolic content [36]. Barroga et al. [37], reported that total phenolic content in Arhar was reduced by $23.39 \%$ and $13.61 \%$, while germinated for 12 and 24 hours, respectively. In the first 12 hours of germination, a huge reduction for $48.7 \%$ was recorded in masur [38].

TAC was increased in some wheat derivatives during soaking and germination and was reduced in few samples. The study showed that TAC content in germinated wheat flours was significantly higher as compared to ungerminated flour. Similar to this study, relatively increased TAC in coloured wheat flours relative to white wheat flours was reported earlier [39-42]. Similarly, higher antioxidant activity and TAC in sprouts of colored wheat grains over white wheat was reported by Sytar et al. [43]. There was a significantly higher anthocyanin content in the sprouts of the purple wheat derivatives than in the blue or yellow wheat derivatives [44].

\section{CONCLUSION}

In conclusion, the observations in the current study suggested a variation in quality parameters of wheat derivatives due to soaking and germination process is useful for their nutritional significance in human diet. However, sensory evaluation of germinated or soaked material will give additional information about its acceptability. The outcome of the study may be validated by in vivo studies for beneficial impact on human health. Moreover, molecular characterization of altered responses may be carried out for a greater insight and further validation with inclusion of more parameters will be the emphasis in future studies.

\section{LIST OF ABBREVIATIONS}

S: Soaking; G: germination; WS: wheat seeds; TPC: Total phenolics content; TAC: Total anthocyanin content. 


\section{ACKNOWLEDGMENTS}

The authors acknowledge the financial support provided by Department of Biotechnology (DBT), Govt. of India (Grant No. BT/AGR/BIOFORTI/PHII/NIN/2011) to conduct the part of this study and Ministry of Food Processing Industries (MoFPI), Govt. of India for infrastructure facility development at Eternal University, Baru Sahib.

\section{CONFLICTS OF INTEREST}

The authors report no financial or any other conflicts of interest in this work.

\section{ETHICAL APPROVALS}

This study does not involve experiments on animals or human subjects.

\section{REFERENCES}

1. Verma M, Saxena A, Sangwan P, Sheikh I, Kumar V, Dhaliwal H. Phytase mediated beneficial impact on nutritional quality of biofortified wheat genotypes. Curr Nutr Food Sci 2020;16:1-16; doi:1 $0.2174 / 1573401316999200901172600$

2. Saxena A, Verma M, Singh B, Sangwan P, Yadav AN, Dhaliwal HS, et al. Characteristics of an acidic phytase from Aspergillus aculeatus APF1 for dephytinization of biofortified wheat genotypes. Appl Biochem Biotechnol 2019;191:679-694.

3. Nathani S, Kumar V, Dhaliwal HS, Sircar D, Roy P. Biological application of a fluorescent zinc sensing probe for the analysis of zinc bioavailability using caco-2 cells as an in-vitro cellular model. J Fluoresc 2020;30:1553-65.

4. Sheikh I, Sharma P, Verma SK, Kumar S, Kumar N, Kumar S, et al. Development of intron targeted amplified polymorphic markers of metal homeostasis genes for monitoring their introgression from Aegilops species to wheat. Mol Breed 2018;38:1-11.

5. Lehmann U, Robin F. Slowly digestible starch-its structure and health implications: a review. Trends Food Sci Technol 2007;18:346-55.

6. Frias J, Fornal J, Ring SG, Vidal-Valverde C. Effect of germination on physico-chemical properties of lentil starch and its components. LWTFood Sci Technol 1998;31:228-36.

7. Dykes L, Rooney L. Phenolic compounds in cereal grains and their health benefits. Cereal Food World 2007;52:105-11.

8. Mattila P, Pihlava JM, Hellström J. Contents of phenolic acids, alkyland alkenylresorcinols, and avenanthramides in commercial grain products. J Agric Food Chem 2005;53:8290-5.

9. Li L, Shewry PR, Ward JL. Phenolic acids in wheat varieties in the health grain diversity screen. J Agric Food Chem 2008;56:9732-9.

10. King A, Young G. Characteristics and occurrence of phenolic phytochemicals. J Acad Nutr Diet 1999;99:213-8.

11. Mazza G. Anthocyanins and heart health. Ann Ist Super Sanita 2007;43:369.

12. Kähkönen MP, Heinonen M. Antioxidant activity of anthocyanins and their aglycons. J Agric Food Chem 2003;51:628-33.

13. Philpott M, Lim CC, Ferguson LR. Dietary protection against free radicals: a case for multiple testing to establish structure-activity relationships for antioxidant potential of anthocyanic plant species. Int J Mol Sci 2009; 10:1081-103.

14. Tsuda T, Horio F, Osawa T. Cyanidin 3-O- $\beta$-D-glucoside suppresses nitric oxide production during a zymosan treatment in rats. J Nutr Sci Vitaminol 2002;48:305-10.

15. Zhao C, Giusti MM, Malik M, Moyer MP, Magnuson BA. Effects of commercial anthocyanin-rich extracts on colonic cancer and nontumorigenic colonic cell growth. J Agric Food Chem 2004; $52: 6122-8$.
16. Hussain I, Uddin MB. Optimization effect of germination on functional properties of wheat flour by response surface methodology. Int Res J Plant Sci 2012;3:031-7.

17. Bohoua GL, Yélakan CKK. Effect of germinated sorghum flour on the performance of laying hens (Warren). Int J Poult Sci 2007;6:122-4.

18. Vidal-Valverde C, Frias J, Sierra I, Blazquez I, Lambein F, Kuo YH. New functional legume foods by germination: effect on the nutritive value of beans, lentils and peas. Eur Food Res Technol 2002;215:472-7.

19. Hübner F, Arendt EK. Germination of cereal grains as a way to improve the nutritional value: a review. Crit Rev Food Sci Nutr 2013;53:853-61.

20. Bradford M. The Bradford assay. Anal Biochem 1976;72:248-54.

21. Hodge J, Hofreiter B. Determination of reducing sugars and carbohydrates. Methods in carbohydrate chemistry In: Whistler RL and Be Miller JN (eds.). Acad Press, New York, NY, 1962.

22. Chen Z, Yu L, Wang X, Gu Z, Beta T. Changes of phenolic profiles and antioxidant activity in canaryseed (Phalaris canariensis L.) during germination. Food Chem 2016;194:608-18.

23. Abdel-Aal ES, Hucl P. A rapid method for quantifying total anthocyanins in blue aleurone and purple pericarp wheats. Cereal Chem 1999;76:350-4.

24. Hung PV, Maeda T, Yamamoto S, Morita N. Effects of germination on nutritional composition of waxy wheat. J Sci Food Agric 2012;92:667-72.

25. Inyang $\mathrm{C}$, Zakari U. Effect of germination and fermentation of pearl millet on proximate, chemical and sensory properties of instant "Fura"-a Nigerian cereal food. Pak J Nutr 2008;7:9-12.

26. Hung PV, Maeda T, Yamamoto S, Morita N. Effects of germination on nutritional composition of waxy wheat. J Sci Food Agric 2012;92:667-72.

27. Megat Rusydi M, Noraliza C, Azrina A, Zulkhairi A. Nutritional changes in germinated legumes and rice varieties. Int Food Res J 2011;18(2); 705-713.

28. Veluppillai S, Nithyanantharajah K, Vasantharuba S, Balakumar S, Arasaratnam V. Biochemical changes associated with germinating rice grains and germination improvement. Rice Sci 2009;16:240-2.

29. Singh Ak, Rehal J, Kaur A, Jyot G. Enhancement of attributes of cereals by germination and fermentation: a review. Crit Rev Food Sci Nutr 2015;55:1575-89.

30. Xie XS, Cui SW, Li W, Tsao R. Isolation and characterization of wheat bran starch. Int Food Res J 2008;41:882-7.

31. Chu S, Hasjim J, Hickey LT, Fox G, Gilbert RG. Structural changes of starch molecules in barley grains during germination. Cereal Chem 2014;91:431-7.

32. Magazù S, Migliardo F, Telling M. Structural and dynamical properties of water in sugar mixtures. Food Chem 2008;106:1460-6.

33. Guo X, Li T, Tang K, Liu RH. Effect of germination on phytochemical profiles and antioxidant activity of mung bean sprouts (Vigna radiata). J Agric Food Chem 2012; 60:11050-5.

34. Marton M, Mandoki Z, Csapo-Kiss Z, Csapo J. The role of sprouts in human nutrition. A review. Acta Univ Sapientiae 2010;3:81-117.

35. Rice-Evans CA, Miller NJ, Paganga G. Structure-antioxidant activity relationships of flavonoids and phenolic acids. Free Radic Biol Med 1996;20:933-56.

36. Singh A, Sharma S, Singh B, Kaur G. In vitro nutrient digestibility and antioxidative properties of flour prepared from sorghum germinated at different conditions. J Food Sci Technol 2019;56:3077-89.

37. Barroga CF, Laurena AC, Mendoza EMT. Polyphenols in mung bean [Vigna radiata (L.) Wilczek]: determination and removal. J Agric Food Chem 1985;33:1006-9.

38. Dicko MH, Gruppen H, Traoré AS, van Berkel WJ, Voragen AG. Evaluation of the effect of germination on phenolic compounds and antioxidant activities in sorghum varieties. J Agric Food Chem 2005;53:2581-8.

39. Abdel-Aal E-SM, Hucl P, Rabalski I. Compositional and antioxidant properties of anthocyanin-rich products prepared from purple wheat. Food Chem 2018;254:13-9. 

biofortified wheat derivatives 2021;9(05):20-25

40. Abdel-Aal E-SM, Hucl P. Composition and stability of anthocyanins in blue-grained wheat. J Agric Food Chem 2003;51:2174-80.

41. Sharma S, Chunduri V, Kumar A, Kumar R, Khare P, Kondepudi $\mathrm{KK}$, et al. Anthocyanin bio-fortified colored wheat: nutritional and functional characterization. PloS One 2018;13:1-16.

42. Liu Q, Qiu Y, Beta T. Comparison of antioxidant activities of different colored wheat grains and analysis of phenolic compounds. J Agric Food Chem 2010;58:9235-41.

43. Sytar O, Bośko P, Živčák M, Brestic M, Smetanska I. Bioactive phytochemicals and antioxidant properties of the grains and sprouts of colored wheat genotypes. Molecules 2018;23:1-14.

44. Jing P, Giusti MM. Contribution of berry anthocyanins to their chemopreventive properties. In: Stoner GD, Seeram NP (eds.). Berries and cancer prevention. Springer, New York, NY, pp 3-40, 2011; doi:10.1007/978-1-4419-7554-6

How to cite this article:

Verma M, Kumar V, Sheikh I, Sangwan P, Bora RS, Yadav AN,

Dhaliwal HS. Beneficial effects of soaking and germination

on nutritional quality and bioactive compounds of biofortified wheat derivatives. J Appl Biol Biotech 2021; 9(05):20-25. 